\title{
An Apology.
}

In an article which was published in the April number of the REviEw, on " Some Problems of Surgery in a Leprosy Colony," we apologise that in printing a photograph of Purulia Leprosy Hospital we inadvertently omitted to acknowledge that this was reproduced by the kind permission of The Mission to Lepers.

We should like to take this opportunity of saying that this institution is the largest that the Mission has in India, and we would remind our readers of a fact which tends to be overlooked, namely, that the Mission to Lepers was the first organisation to engage in leprosy work on an extensive scale. It was largely their work in India that stimulated further aid on behalf of the cause of leprosy. The Mission to Lepers maintains 47 homes and has under its care some 10,000 cases. 